\title{
COMPETÊNCIA INFORMACIONAL NA PERSPECTIVA DOS ESTUDANTES DE CIÊNCIAS CONTÁBEIS
}

\section{INFORMATIONAL COMPETENCE IN THE PERSPECTIVE OF ACCOUNTING SCIENCES STUDENTS}

\author{
Cristiano Moreiraa \\ Joana Carlos Beirab \\ Marta Maputere \\ Ricardo Rodrigues Barbosad
}

\begin{abstract}
RESUMO
Introdução: Avaliar as perspectivas dos usuários da informação e suas habilidades no que tange às competências informacionais se torna necessário para entender como as novas maneiras e formas de organizar as informações estão chegando a seus usuários e se elas estão causando algum tipo de impacto positivo na execução das suas atividades profissionais e cotidianas. A Ciência Contábil é um curso no qual a gestão e a organização de informação são um insumo necessário para o eficiente desempenho das atividades profissionais. Assim, buscar entender a expectativa e o entendimento dos discentes dessa área pode ser um importante instrumento para compreender os impactos dessas novas habilidades. Objetivo: o presente estudo buscou responder à seguinte indagação: Qual o entendimento dos discentes do curso de Ciências Contábeis sobre algumas práticas vinculadas as competências informacionais? Metodologia: A pesquisa é classificada como descritiva, de levantamento misto (quali e quanti). Para tanto, foi empregada a estatística descritiva. A amostra foi não probabilística, composta por 200 discentes do curso de ciências contábeis de instituições públicas e privadas. Resultados: Os resultados apontaram que grande parte dos entrevistados apresentou elevado percentual das competências informacionais. Conclusões: Apesar de ter sido apresentado um elevado conhecimento nas práticas que envolvem estas competências, quando se tratam de práticas e termos mais usuais na Ciência da Informação, esses percentuais diminuem consideravelmente, sinalizando a necessidade de uma maior integração dessas duas ciências para ampliar o desempenho desses futuros profissionais.
\end{abstract}

a Doutorando em Gestão e Organização do Conhecimento da Universidade Federal de Minas Gerais (UFMG). E-mail: cristianomoreirasilva@hotmail.com.

b Doutorando em Gestão e Organização do Conhecimento da Universidade Federal de Minas Gerais (UFMG). E-mail: joanabeira@yahoo.com.br.

c Doutorando em Ciência da Informação da Universidade Federal de Minas Gerais (UFMG). Email: martamaputere@gmail.com.

d Doutor em Administração de Empresas pela Columbia University, Estados Unidos. Docente no Programa de Pós-Graduação em Gestão e Organização do Conhecimento da Universidade Federal de Minas Gerais (UFMG). E-mail: ricardobarbosa@ufmg.br 
Descritores: Competência Informacional. Literatura da Informação. Ciências Contábeis. Gestão do Conhecimento.

\section{INTRODUÇÃO}

A Ciência da Informação $(\mathrm{Cl})$ é uma ciência relativamente nova, e sua definição vem sofrendo modificações evolutivas desde a década de 1960, ou seja, desde o período do pós-guerra. Atualmente, uma das definições possíveis para a $\mathrm{Cl}$ refere-se ao estudo da coleta, organização, armazenamento, recuperação e disseminação da informação, sendo uma área que cruza ou trespassa as disciplinas convencionais (MIRANDA, 2007). Trata-se de uma área cujos fundamentos e princípios podem fundamentar o desenvolvimento de sistemas capazes de atender às necessidades informacionais da população, fornecendo, em tempo hábil, informações úteis e confiáveis e essenciais para as tomadas de decisões.

Vários estudiosos denominam a sociedade contemporânea como a sociedade da informação e do conhecimento (MIRANDA, 2004). Nesse contexto, devido ao crescimento exponencial do conhecimento, o homem moderno vem sofrendo um "bombardeio" informacional de vários tipos, obrigando-o a se manter em constante atualização, seja no contexto social, seja no contexto profissional, buscando estar sempre conectado ao que está acontecendo no mundo (ALVES, 2011).

Essa necessidade de atualização tem contribuído e influenciado em praticamente todas as áreas do conhecimento, como, por exemplo, a Biblioteconomia, cujas práticas contribuíram para o surgimento de novos termos com o intuito de representar de forma mais objetiva e direta a informação. Um dos termos adotados é a competência informacional (information literacy), adotado primeiramente nos Estados Unidos para definir habilidades ligadas ao uso da informação eletrônica (CAMPELLO, 2003).

No contexto internacional, o uso do termo competência informacional vem gerando inúmeros debates direcionados para a complexidade em se ter um conceito único, uma vez que, para ser observado como objeto, é necessário analisar o termo em suas várias formas possíveis. Desse modo, o termo 
competência informacional tem sido empregado para definir o conjunto de habilidades necessárias para o entendimento das informações oferecidas em um ambiente totalmente complexo (CAMPELLO, 2006).

Outro olhar que se pode ter sobre a temática é a concepção introduzida por Miranda (2004), que destaca a competência informacional como sendo o agrupamento de competências profissionais e organizacionais que estão alicerçadas profundamente em informação, sendo externada através da experiência em lidar com os ciclos informacionais, os quais correspondem às novas tecnologias e aos ambientes nos quais estão inseridas.

Portanto, a competência informacional está diretamente relacionada a todas as áreas do Conhecimento e, por isso, é importante compreender os modos de se lidar com as informações com o intuito de gerar conhecimento para auxiliar nas tomadas de decisão.

Nesse sentido, é válido ressaltar que, embora a Ciência da Informação tenha sua origem em diferentes outros campos, pode fornecer conceitos, prática se metodologias para outras áreas que também lidam com o objetivo informação (MIRANDA, 2007). Nessa perspectiva, a Contabilidade é um importante instrumento de geração e fornecimento de informações para a avaliação do desempenho empresarial. Isso é possível porque a Contabilidade é utilizada por inúmeros agentes (Governo, funcionários, instituições financeiras, etc.) com o intuito de representar e conhecer um pouco mais a realidade em que está inserida, sendo uma importante área que contribui para a existência da estabilidade do funcionamento da vida socioeconômica (GASPARETTO, 2004; BRANCO, 2006).

Assim sendo, muitas das competências informacionais técnicas necessárias para o bom desenvolvimento da atividade profissional do Contador devem ser fornecidas durante a sua Graduação, uma vez que irão fornecer subsídios para que esse profissional tenha o conhecimento mínimo necessário para lidar em seu dia a dia com as situações que lhe serão apresentadas. Diante desse contexto, a indagação que norteou essa pesquisa foi: Qual o entendimento dos discentes do curso de Ciências Contábeis sobre algumas práticas vinculadas as competências informacionais? 
O tema se torna relevante por iniciar uma discussão de como estão sendo apresentadas a esses alunos as informações necessárias para sua formação, com enfoque na ampliação de seu conhecimento e desenvolvimento de determinadas competências informacionais. Outro ponto importante deste estudo é buscar verificar o entendimento dos profissionais que estão inseridos no mercado a respeito dessa temática, avaliando se existe alguma falha nesse processo, e se os futuros profissionais têm o entendimento de quais competências informacionais são necessárias para o desenvolvimento de suas atividades.

\section{REFERENCIAL TEÓRICO}

Nesta seção, serão apresentadas algumas teorias sobre competências informacionais que se relacionam com a gestão do conhecimento, bem como as principais características do profissional que atua na área contábil e alguns estudos no âmbito nacional e internacional que estão diretamente atrelados com o assunto discutido nesta pesquisa.

\subsection{COMPETÊNCIAS INFORMACIONAIS}

As pesquisas sobre competência informacional são variadas e descritas no campo da Ciência da Informação em diversas perspectivas, com abordagens focadas em diferentes contextos, grupos, sendo que as mais tradicionais pesquisas focam no uso da informação, no contexto escolar e nas Instituições de Ensino Superior (IES).

A expressão information literacy "surgiu na década de 1970, nos Estados Unidos, para designar habilidades necessárias à utilização de bases de dados eletrônicas que estavam sendo comercializadas naquele país desde a década de 1960" (CAMPELLO, 2006, p. 65). No entanto, desde o seu cunho por Paul Zurkowski, pesquisas e definições de competência informacional crescem na literatura no campo da Ciência da Informação, sendo que não existe uma definição única e consensual por parte dos pesquisadores. Como consequência, existe uma série de conceitos de competência informacional na literatura vigente, 
mas a definição mais aceita e citada é a apresentada pela American Library Association (ALA).

Em 1989, a American Library Association (ALA), em seu relatório final do Presidential Committee on Information Literacy, julgou que 0 indivíduo competente em informação deve

[...] ser preparado para identificar quando a informação é necessária e ter a habilidade para localizar, avaliar e usar efetivamente a informação. [...] Pessoas competentes informacionais são aquelas que aprenderam a aprender". Seguindo a concepção da necessidade de localização, avaliação e uso da informação, a competência informacional também tem sido relacionada a habilidades em lidar com as tecnologias de informação (AMERICAN LIBRARY ASSOCIATION, 1989 citado por VITORINO; PIANTOLA, 2009, p. 134).

Para a Association of College and Research Libraries (ACRL), a competência informacional permite ao aluno: i) determinar a extensão da informação necessária; ii) aceder à informação de que necessita de um modo eficaz e eficiente; iii) avaliar criticamente a informação e as suas fontes; iv) incorporar a informação selecionada na sua base de conhecimentos; v) usar a informação eficazmente de modo a responder a um objetivo específico; vi) compreender as questões econômicas, legais e sociais que envolvem o uso da informação; e vii) aceder e utilizar a informação de um modo ético e legal (ACRL, 2000).

Dentro dessa linha de pensamento, a competência informacional é comumente definida como a capacidade de encontrar, acessar, avaliar e utilizar informações de forma eficaz para responder a uma determinada situação, e tem suas raízes na biblioteca tradicional ou instrução bibliográfica (BRUCE, 2003; SAUNDERS, 2012).

De acordo com Bruce (2003), a competência informacional é percebida em um contexto em que existe um conjunto de habilidades que um indivíduo deve ter para localizar, gerenciar e utilizar informações de forma eficaz com o intuito de responder à necessidade de informação. Essas habilidades permitem que as pessoas lidem efetivamente com a tomada de decisões e assumam a responsabilidade por sua própria aprendizagem e formação ao longo da vida nas áreas de interesse pessoal ou no âmbito profissional. 
Para finalizar, Bruce (2003) apresenta sete categorias da competência informacional. A primeira categoria diz respeito ao uso da Tecnologia da Informação e Comunicação para a recuperação a informação, em que a competência informacional depende da avaliação e do uso das informações, visto que o indivíduo precisa analisar o ambiente de informação para alcançar um elevado nível de conhecimento. A segunda refere-se ao conhecimento de fontes de informação, em que a competência informacional visa encontrar as informações diante de variados suportes de informação e ter a capacidade de acessá-los de forma independente ou através de um intermediário. A terceira categoria é baseada nos processos de informação e na capacidade de criar estratégias para enfrentar situações novas. A quarta fundamenta-se no controle da informação pelo usuário e diz respeito à organização, ao armazenamento e, posteriormente, à recuperação da informação quando necessário. A quinta categoria é baseada na construção do conhecimento tendo em conta o uso crítico da informação de modo a construir uma base de conhecimento pessoal. A sexta categoria é alicerçada na extensão do conhecimento, pautado pelo uso e pela apropriação da informação para gerar novos conhecimentos. Por fim, a sétima categoria é fundamentada na utilização sábia do conhecimento em benefício pessoal ou da sociedade em que está inserida. Essa última categoria envolve valores pessoais, atitudes e crenças em relação ao uso da informação de forma racional em variados contextos.

Outra definição é proposta por Johnston e Webber (2003), que definem a competência informacional como

[...] a adoção de comportamento informacional apropriada para obter, por meio de qualquer canal ou meio, de informações bem equipado para as necessidades de informação, juntamente com consciência crítica sobre a importância do uso sábio e ético da informação na sociedade (JOHNSTON; WEBBER, 2003, p. 336).

Nessa definição, os autores destacam o comportamento informacional, o transporte de informação e a apropriação e uso da informação de forma adequada e eficaz, respeitando as questões legais e de direitos autorais.

Na concepção de Dudziak (2003) e Belluzzo, (2006), a competência informacional deve ser entendida como um processo contínuo que promove a 
interação e internalização de fundamentos conceituais que envolvem atitudes e habilidades necessárias, bem como um requisito específico para compreender e interagir de forma permanente em um contexto de diversidade informacional de forma independente, de modo a proporcionar um aprendizado ao longo da vida.

Dudziak (2003) acrescenta que o desenvolvimento da competência em informação como um processo de busca da informação para a produção do conhecimento envolve o uso, a interpretação, os significados, a construção de modelos e a hierarquização mentais, e não apenas uma resposta às perguntas. Desse modo, de acordo com o autor, a competência informacional envolve, também, o aprendizado e a capacidade de criar significados a partir da informação. Hoje, a competência informacional está intimamente associada com as práticas informacionais e com o pensamento crítico no ambiente de tecnologia da informação e comunicação (TIC), e é a base para o aprendizado em um ambiente contemporâneo de mudança tecnológica contínua (BRUCE, 2003).

A definição do Lupton et al. (2004) vai além de habilidades de pesquisa bibliográfica e de competência no uso das tecnologias de comunicação e informação (TICs), uma vez que, para os autores, a competência informacional deve ser vista na perspectiva de análise de ordem superior, que envolve a síntese, o pensamento crítico e a resolução de problemas. Nessa perspectiva, o indivíduo busca e utiliza as informações para a aprendizagem independente e, ao longo da vida, participar ativamente da cidadania e da responsabilidade social.

Em suma, é possível notar que não existe uma definição única para conceituar o termo competência informacional, mas percebe-se, a partir da literatura existente, que os autores reconhecem sua importância para 0 desenvolvimento das habilidades do indivíduo e exortam aos bibliotecários a repensarem seu trabalho, ensinando aos estudantes as habilidades de ordem superior que envolvem o pensamento crítico da informação, bem como 0 questionamento das fontes e uso da informação como resolução de problemas em determinado contexto. 


\subsection{COMPETÊnCIAS INFORMACIONAIS E GESTÃo do CONHECIMENTO}

Com o atual desafio da sociedade tida como sociedade da informação e do conhecimento, a informação passou a constituir-se um dos principais fatores de produção, o qual representa grandemente os valores agregados dos produtos (MIRANDA, 2004; MELO; ARAÚJO, 2007). Portanto, a necessidade de repensar a compreensão e o desenvolvimento de habilidades práticas para o uso da informação e das tecnologias disponíveis atualmente surge como uma grande preocupação na medida em que procuramos perceber até que ponto a aplicabilidade das principais hipóteses teóricas e estruturas da competência informacional desenvolvidas para fins acadêmicos podem atender às situações de trabalho em tempo real (O'FARRILL, 2008).

Nesse sentido, muitos autores recomendam o aprimoramento dos estudos sobre a teoria de aprendizagem e das práticas acadêmicas, visto que as diferentes maneiras pelas quais os processos de aprendizagem são compreendidos na teoria e abordados na prática são responsáveis por uma parte importante da dificuldade de conectar posições em toda a literatura de Biblioteconomia e Ciência da Informação (LIS) e Gestão do Conhecimento. (O'FARRILL, 2008, p. 156).

Assim, ao analisar sob o ponto de vista dos benefícios que a competência informacional pode oferecer aos indivíduos, Santos et al. (2008) destacam três características, a saber, as expertises, as habilidades e as capacidades. Nesse sentido, Miranda (2004) explica que falar de competências, ao invés de qualificação para um emprego ou um determinado posto de trabalho, envolve a redefinição do significado da qualificação, em que o alvo será a pessoa com suas características mais completas.

Além disso, na literatura vigente, a competência informacional é compreendida como o subconjunto do aprendizado independente contido no aprendizado ao longo da vida (lifelong learning) (Cf. MELO; ARAÚJO, 2007; FARIA; VITORINO, 2009; BEM; COELHO, 2015). Nessa linha de pensamento esse tipo de aprendizado abrange um conjunto de habilidades e conhecimentos, incluindo a localização e o uso da informação para a resolução de problemas e tomadas de decisão. Abrange desde os processos de busca da informação para 
a construção do conhecimento pelas habilidades em tecnologia da informação, até $\mathrm{o}$ aprendizado independente, por meio da interação social dos sujeitos. (FARIA; VITORINO, 2009). Essas autoras relacionam e agrupam as atividades da gestão do conhecimento com habilidades que formam a competência informacional em dois níveis, a saber:

Nível tácito - a obtenção do conhecimento leva ao exercício da
habilidade de busca da informação; o uso desse conhecimento
exercita a habilidade de usar a informação para a solução de
problemas; o aprendizado do conhecimento requer a habilidade
de organizar a informação; por fim, contribuir com o
conhecimento leva ao exercício da habilidade de compartilhar a
informação.
Nível estratégico - a construção e a manutenção do
conhecimento depreendem as habilidades de identificar, de
reconhecer a necessidade e de acessar a informação; a
avaliação do conhecimento é sinônimo da avaliação da
informação e, para descartar determinado conhecimento,
necessita-se de um conjunto de habilidade de competência
informacional (MELO; ARAÚJO, 2007, p. 197).

A relação entre a competência informacional e a gestão do conhecimento ocorre mediante o uso eficaz de sistemas de informação e dos processos de aprendizagem que estão implícitos nas tarefas de criação e de transferência de conhecimento. (O'FARRILL, 2008, p. 156). Entretanto, a criação do conhecimento organizacional depende do conhecimento das pessoas, da motivação e da vontade de criar, agir, compartilhar e codificar seu próprio conhecimento individual. Já a gestão do conhecimento centra-se em entender o que os colaboradores consideram fazer bem e tirar proveito desse conhecimento com a maior eficiência possível (FARIA et al., 2005).

Desse modo, o conhecimento é um elemento diferenciado para as organizações que buscam a excelência, uma vez que, sem o conhecimento, o potencial humano se torna instável, inviabilizando todo o processo de geração de produtos e serviços coerentes com as demandas internas e externas. Independentemente do modelo que as organizações adotem para a criação do conhecimento organizacional, terão de fazer frente a muitos desafios. (BEM; COELHO, 2015).

A gestão do conhecimento terá como base as habilidades para contribuir com a formação da competência informacional, pois relaciona-se diretamente 
com as atitudes que facilitam a criação e o compartilhamento do conhecimento, levando a um aprendizado ao longo da vida. (MELO; ARAÚJO, 2007). Em uma organização, a evolução do trabalho com o conhecimento está diretamente relacionada ao desenvolvimento estratégico de suas competências, conforme propõem Faria et al. (2005).

\subsection{Profissional da Área ContábIL}

Uma das principais funções das Universidades é inserir, na sociedade, profissionais em plenas condições para o exercício de suas atividades. As rápidas transformações que a sociedade sofre, oriundas da globalização e das evoluções tecnológicas, obrigam as instituições a formarem profissionais que, além das capacidades técnicas, possuam uma visão multidisciplinar, ultrapassando a complexidade do conhecimento científico. (LOUSADA; MARTINS, 2005).

Apesar da importância da competência informacional no curso de Ciências Contábeis, educadores de contabilidade são, muitas vezes, resistentes em incorporar as práticas relacionadas ao desenvolvimento dessas habilidades em suas aulas ao lado de um currículo já pesado com regras, regulamentos e outras habilidades específicas impostas pelo setor. (FINLEY; WAYMIRE, 2012).

É importante destacar que a área de atuação do profissional contábil é um universo muito amplo, podendo atuar na área pública, na controladoria, na perícia contábil e em inúmeras outras áreas. Além disso, esse profissional pode trabalhar como profissional autônomo, como empregado em uma sociedade empresária ou em empresas públicas por meio de concurso. O profissional dessa área vai lidar no seu dia a dia com um bem que é apontando como o mais precioso da economia, a saber, a informação contábil, o que coloca esse profissional em posição de destaque perante à sociedade em geral, contextualizando-o historicamente, socialmente e culturalmente. (NOGUEIRA; FARIA, 2006).

O perfil do profissional contábil irá se modificar e acompanhar as necessidades introduzidas pelas novas demandas do mercado, com base nos conhecimentos adquiridos em eventos do passado e do presente. Desse modo, 
esse profissional deve possuir uma visão ampla de projeções para o futuro. (EVANGELISTA, 2005). Um modelo do processo dessas transformações está representado na figura 1 a seguir.

Figura 1 - Mudanças no perfil do profissional Contador
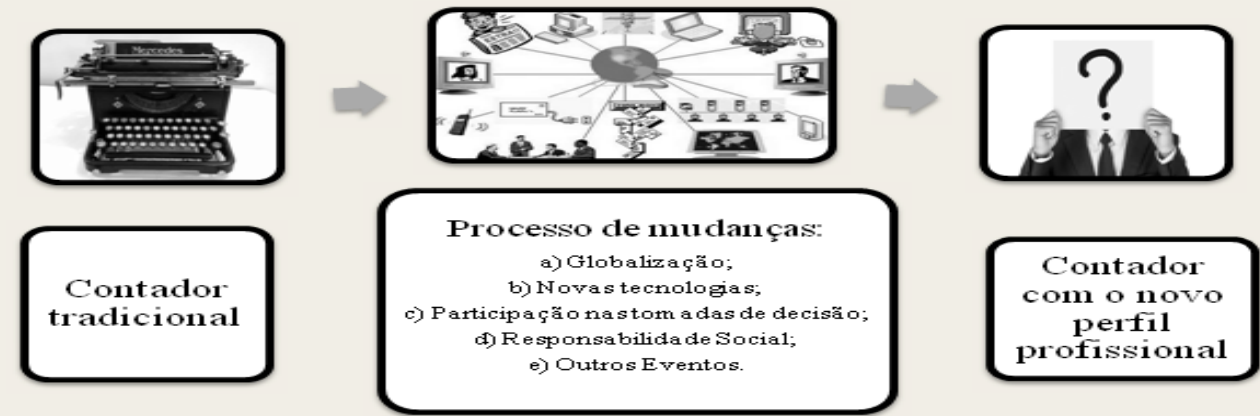

Fonte: Elaborado com base em (EVANGELISTA, 2005)

O contador precisa estar apto a atender às demandas da sociedade no seu dia a dia, pois as mudanças impactam a sua profissão. Além disso, as competências informacionais estão atreladas ás habilidades de se adequar, sendo que muitos desses processos irão ocorrer após a finalização do curso superior, quando o profissional já estiver em pleno exercício de suas atividades profissionais.

\subsection{ESTUdOS ANTERIORES NACIONAIS E INTERNACIONAIS}

Em sua pesquisa, Kelly et al. (2011) utilizaram dois grupos de alunos voluntários matriculados na disciplina de introdução à Contabilidade para participarem de um estudo pedagógico com o intuito de avaliar a sua competência informacional. Apenas um dos grupos tinha acesso às instruções e informações necessárias para desenvolver competências com o auxílio de bibliotecários que forneceram três encontros com orientações, sendo que os discentes tiveram um semestre para avaliar potenciais negócios empresariais.

Os resultados dessa pesquisa apontaram que o grupo que teve acesso às orientações, apresentaram um melhor desempenho, quando comparado ao segundo grupo, que não teve acesso a esse tipo de informação. Esses resultados, segundo os autores, encorajam as práticas de integração da biblioteca integrada no curso e na instrução, sendo o reforço direcionado pela biblioteca necessário para o desenvolvimento do aluno. Uma das limitações 
presentes no estudo de Kelly et al. (2011) foi a aplicação do experimento em uma única instituição de ensino, o que limitou a generalização dos resultados da pesquisa.

Dando sequência, outro estudo que analisou esse perfil de usuários foi o empreendido por Finley e Waymire (2012), que examinaram o ensino de competências informacionais aplicado aos estudantes de contabilidade, através de um estudo de caso elaborado por dois tipos de profissionais, sendo um professor de contabilidade e um bibliotecário especialista na área de negócios. Essa pesquisa contribuiu para tratar o desconhecimento dos discentes sobre como encontrar e incorporar fontes de informações confiáveis em seus estudos.

Após os resultados desse estudo, os pesquisadores elaboraram um projeto aplicado a uma turma de Contabilidade Governamental, visando identificar e desenvolver uma visão crítica por parte dos alunos e contribuindo para formar uma opinião sobre o tema. No momento final desse projeto, foi realizada uma análise das fontes de informação que eles utilizaram para sustentar as suas opiniões. Após a elaboração do relatório, este foi submetido a uma revisão por pares, formados pelos próprios integrantes da turma, que avaliaram os achados do colega. Adotando uma pontuação que avaliava a competência informacional em cada momento, foi possível observar uma melhora significativa nos resultados finais apresentados, bem como uma melhoria na confiança dos alunos. Os autores deixaram como sugestão o uso de projetos similares aplicados em currículos de Contabilidade para erradicar ou diminuir possíveis déficits de competências informacionais presentes em outras disciplinas.

Por último, a pesquisa empreendida por Xavier et al. (2013), a qual foi base para o desenvolvimento deste estudo, buscou analisar a percepção dos discentes concluintes do curso superior em Administração em uma instituição de Ensino Superior de Salvador no que tange ao nível de competência informacional. Através da análise das 36 respostas das 80 possíveis, os autores identificaram que, das nove categorias avaliadas, a média mais elevada foi observada na categoria "organizar", concluindo que o nível de competências presentes nos estudantes se enquadrou no modelo Seven Pillars, desenvolvido pela Society of college, National and University Libraries - SONUL. 


\section{METODOLOGIA}

A pesquisa científica é a atividade básica da ciência na indagação e na construção da realidade (MAÇANEIRO; KUHL, 2013), uma vez que se trata da realização de um estudo planejado, sendo o método de abordagem do problema o que caracteriza o aspecto científico da investigação. Nesse sentido, a finalidade da pesquisa científica é descobrir respostas para questões mediante a aplicação do método científico. A pesquisa sempre parte de um problema, de uma interrogação, uma situação para a qual o repertório de conhecimento disponível não gera resposta adequada (PRODANOV; FREITAS, 2009).

Quanto à abordagem, utilizou-se, como estratégia, a abordagem mista (quali-quanti). Com relação à classificação da pesquisa, utilizou-se o estudo exploratório e o descritivo. Segundo Prodanov e Freitas (2009), o objetivo de um estudo exploratório é familiarizar-se com um tópico ou identificar conceitos iniciais sobre ele, dando atenção na determinação de quais compressões devem ser aplicadas em determinado fenômeno e como realizar a medição dessas compressões, buscando descobrir novas possibilidades da população que se pretende estudar (FREITAS et al., 2000).

A pesquisa descritiva tem como característica a descrição dos principais atributos de determinada população ou fenômeno, buscando estabelecer possíveis relações, ou seja, as informações são observadas, analisadas, registradas, classificadas e interpretadas sem que o pesquisador interfira sobre elas (PRODANOV; FREITAS, 2009). No presente estudo, buscou-se identificar qual o entendimento dos discentes do curso de Ciências Contábeis sobre o que são competências informacionais.

O método empregado para se obter essas evidências foi a adoção de um survey, já validado no estudo de Xavier et al. (2013). O survey foi feito através do questionário aplicado aos discentes de cursos de Ciências Contábeis e disponibilizado via internet, através de e-mails, redes sociais e aplicativos de mensagens instantâneas. Por esse motivo, a amostra deste estudo, constituída de 200 respondentes de instituições brasileiras públicas e privadas, é considerada não probabilística, ou seja, foi utilizada uma amostra por 
conveniência, e o motivo dessa seleção foi a acessibilidade.

Os dados geralmente oriundos desse tipo de pesquisa devem ser analisados por meio de instrumentos estatísticos. Mesmo que as variáveis sejam qualitativas, estas podem ser quantificadas, visto que têm como resultados atributos de qualidade (por exemplo, a variável sexo) e apresentam como resultado os números de determinadas escalas (FREITAS et al., 2000).

Apesar de a pesquisa de Xavier et al. (2013), do qual foram extraídas as questões do questionário, ter usado uma escala de cinco pontos, foi feita a opção de avaliar neste estudo o conhecimento limitando-se a opção de respostas dos participantes, com respostas de "sim" ou "não". Posteriormente, essas informações foram tratadas, transformando-se em linguagem binária, ou seja, $\operatorname{sim}=1$ e não $=0$, para se extrair dessas respostas as estatísticas descritivas.

\section{COLETAS E ANÁLISE DOS RESULTADOS}

Nesta seção, serão expostos os resultados obtidos, bem como as análises desses dados, com o intuito de responder o problema da pesquisa.

\subsection{CaracterizaÇão da Amostra}

$\mathrm{Na}$ tabela a seguir, foram apresentadas as principais características dos respondentes.

Tabela 1 - Caracterização da amostra

\begin{tabular}{|l|c|c|}
\hline Gênero & Frequência & Porcentagem \\
\hline Masculino & 75 & $37,5 \%$ \\
\hline Feminino & 125 & $62,5 \%$ \\
\hline Instituição & & \\
\hline Instituição Privada & 182 & $91,0 \%$ \\
\hline Instituição Pública & 18 & $9,0 \%$ \\
\hline Modalidade & & \\
\hline Presencial & 194 & $97,0 \%$ \\
\hline A distância & 6 & $3,0 \%$ \\
\hline Período & & \\
\hline Primeiro ao segundo & 16 & $8,0 \%$ \\
\hline Terceiro ao quarto & 42 & $21,0 \%$ \\
\hline Quinto ao sexto & 53 & $26,5 \%$ \\
\hline
\end{tabular}




\begin{tabular}{|l|c|c|}
\hline Sétimo ao oitavo & 65 & $32,5 \%$ \\
\hline Final do curso & 24 & $12,0 \%$ \\
\hline Situação no curso & & \\
\hline Primeira graduação & 172 & $86,0 \%$ \\
\hline Não é a primeira graduação & 28 & $14,0 \%$ \\
\hline Estado civil & 142 & \\
\hline Solteiro & 48 & $71,0 \%$ \\
\hline Casado & 10 & $24,0 \%$ \\
\hline Outros & & $5,0 \%$ \\
\hline Idade & 18 & $9,0 \%$ \\
\hline Até 20 anos & 86 & $43,0 \%$ \\
\hline De 21 a 25 anos & 50 & $25,0 \%$ \\
\hline De 26 a 30 anos & 46 & $23,0 \%$ \\
\hline Acima de 30 anos & 2018 & \\
\hline
\end{tabular}

Fonte: Dados da pesquisa, 2018.

Conforme apresentado na tabela $1,62,5 \%$ dos respondentes são do sexo feminino, $91 \%$ são de origem de instituições privadas e $97 \%$ de curso presencial, sendo que $44,5 \%$ dos respondentes estava no final do curso ou no sétimo ou oitavo períodos. Além disso, o segundo maior percentual de respondentes $(26,5 \%)$ foi de alunos que estavam no quinto ou sexto período, ou seja, $59 \%$ dos respondentes já tinham ultrapassado a metade do curso. Os dados revelam também que grande parte dos respondentes (86\%), no momento da realização da pesquisa, estavam cursando a primeira graduação, sendo $71 \%$ solteiros e a faixa etária de maior concentração entre 21 a 25 anos.

\subsection{VARIÁVEIS dos QuestionÁRIOS e ANÁlises dos Resultados}

No presente trabalho foram adotadas as variáveis do estudo de Xavier et al. (2013), apresentadas no quadro 1, para delinear os blocos de análises realizadas das questões apresentadas.

\section{Quadro 1 - Variáveis avaliadas de competências informacionais}

\begin{tabular}{|c|l|c|}
\hline Variáveis & \multicolumn{1}{|c|}{ Características } & Questões \\
\hline Reconhecimento & $\begin{array}{l}\text { Identificar a necessidade informacional, como os conhecimentos } \\
\text { e habilidades necessidades com o intuito de transformar a } \\
\text { informação em conhecimento. }\end{array}$ & 1 a 3 \\
\hline Localização & $\begin{array}{l}\text { Buscar as fontes informacionais necessárias, de maneira e } \\
\text { eficaz. }\end{array}$ & 4 a 5 \\
\hline
\end{tabular}




\begin{tabular}{|c|l|c|} 
Avaliação & $\begin{array}{l}\text { Avaliar os procedimentos adotados para buscar a informação e } \\
\text { também as informações resgatadas na busca. }\end{array}$ & 6 a 7 \\
\hline Organização & $\begin{array}{l}\text { Empregar métodos com o intuito de realizar um eficiente } \\
\text { gerenciamento informacional }\end{array}$ & 8 a 9 \\
\hline Utilização & $\begin{array}{l}\text { Adotar as informações obtidas como insumo para auxiliar nas } \\
\text { tomadas de decisões, resoluções de problemas e para gerar } \\
\text { conhecimento. }\end{array}$ & 10 a 13 \\
\hline Comunicação & $\begin{array}{l}\text { Aplicar métodos eficientes com o intuito de disseminar a } \\
\text { informação e o conhecimento obtido. }\end{array}$ & 14 a 15 \\
\hline Sintetizar & $\begin{array}{l}\text { Buscar sintetizar o que é mais importante, com o intuito de não } \\
\text { sobrecarregar o usuário com informações desnecessárias. }\end{array}$ & 16 a 17 \\
\hline Criação & Aplicar as informações na geração de soluções e conhecimento. & 18 a 19 \\
\hline $\begin{array}{c}\text { Valores } \\
\text { orientados }\end{array}$ & $\begin{array}{l}\text { Buscar conhecer os valores embutidos no processo } \\
\text { informacional. }\end{array}$ & 20 a 21 \\
\hline
\end{tabular}

Fonte: Elaborado pelos autores, com base em Xavier et al. (2013)

Com base nas frequências de respostas às variáveis, foram calculadas as médias e desvios padrões, obtendo-se os resultados presentes nas tabelas a seguir.

Tabela 2 - Resultados obtidos variáveis: Reconhecimento

\begin{tabular}{c|c|c|c|c|c|c|c|c|c}
\hline Ord. & \multicolumn{1}{|c|}{ Questões } & Sim & $\%$ & Não & $\%$ & Média & D.P & $\begin{array}{c}\text { Média } \\
\text { geral }\end{array}$ & $\begin{array}{c}\text { D. P. } \\
\text { Geral }\end{array}$ \\
\hline 1 & $\begin{array}{l}\text { No meu dia a dia quando vivencio } \\
\text { uma situa/problema, já identifico } \\
\text { de imediato as informações } \\
\text { necessárias para aplicar como } \\
\text { possíveis soluções. }\end{array}$ & 193 & 96,5 & 7 & 3,5 & 0,96 & 0,18 & & \\
\hline 2 & $\begin{array}{l}\text { Busco entender bem o problema } \\
\text { para me orientar de quais as } \\
\text { informações serão necessárias } \\
\text { empregar para sua eficiente } \\
\text { solução. }\end{array}$ & 185 & 92,5 & 15 & 7,5 & 0,92 & 0,26 & 0,92 & 0,13 \\
3 & $\begin{array}{l}\text { Tenho o hábito de criar uma lista } \\
\text { com as principais palavras-chave } \\
\text { para me facilitar na busca da } \\
\text { informação. }\end{array}$ & 108 & 54 & 92 & 46 & 0,54 & 0,50 & & \\
\hline
\end{tabular}

Fonte: Dados da pesquisa, 2018.

Conforme dados expostos na tabela 1 , nas questões que buscaram identificar o nível de reconhecimento pelos entrevistados, mais de $90 \%$ dos entrevistados acreditavam que possuíam um amadurecimento para identificar os problemas e buscar as possíveis soluções, identificando as melhores informações para auxiliar na tomada de decisões. Contudo, esse percentual se reduz quando se refere à busca de informações e à manutenção de um eficiente controle de palavras-chaves, ficando em torno de $54 \%$. 
As variáveis que compõe a perspectiva do reconhecimento, segundo 0 estudo de Xavier et al. (2013), estão relacionadas às capacidades dos estudantes de realizar um diagnóstico no que se refere à necessidade de informações que deverão ser utilizadas com o objetivo de serem empregadas em possíveis soluções de demandas. Esses elementos demonstram a importância atribuída pelos discentes em poder antecipar as necessidades informacionais de seus usuários, o que vai ao encontro da segunda questão, que se refere ao entendimento do problema. A este respeito, Barros (2005), afirma que existem necessidades e objetivos distintos quanto à apuração da informação contábil. Ou seja, ela será influenciada por processos e critérios distintos; neste sentido, o entendimento das circunstancias e as possíveis variáveis que influenciam a ocorrência de determinado fato é importante para o exercício profissional.

Porém, ao mesmo tempo que as duas primeiras variáveis sinalizam para uma aderência ao critério de reconhecimento da prática de se criar uma lista de palavras-chaves, fato este pode ser justificado pelo fato desta pratica não ser ensinada em nenhuma das disciplinas oferecidas no curso.

Tabela 3 - Resultados obtidos variáveis: Localização

\begin{tabular}{|c|c|c|c|c|c|c|c|c|c|}
\hline Ord. & Questões & Sim & $\%$ & Não & $\%$ & Média & D.P & $\begin{array}{c}\text { Média } \\
\text { geral }\end{array}$ & $\begin{array}{l}\text { D. P. } \\
\text { Geral }\end{array}$ \\
\hline 4 & $\begin{array}{l}\text { Utilizo vários métodos de } \\
\text { estratégias de pesquisas } \\
\text { adotadas em ambientes } \\
\text { eletrônicos como: truncagem, } \\
\text { operadores, booleanos, } \\
\text { palavras-chave, uso de aspas } \\
\text { etc. }\end{array}$ & 99 & 49,5 & 101 & $\begin{array}{c}50, \\
5\end{array}$ & 0,49 & 050 & \multirow[t]{2}{*}{0,68} & \multirow[t]{2}{*}{0,08} \\
\hline 5 & $\begin{array}{l}\text { Tenho conhecimento das } \\
\text { principais ferramentas da web } \\
\text { disponíveis (navegador da } \\
\text { internet, motores de busca, } \\
\text { mecanismos de comunicação } \\
\text { etc.). }\end{array}$ & 175 & 87,5 & 25 & $\begin{array}{c}12, \\
5\end{array}$ & 0,87 & 0,33 & & \\
\hline
\end{tabular}

Fonte: Dados da pesquisa, 2018.

No que se refere à localização e à adoção de uma boa estratégia de buscas, menos da metade, ou seja, $49,5 \%$ dos discentes reconheceram adotar essa prática. Contudo, a maioria dos entrevistados acreditavam em ter um bom domínio sobre essas ferramentas. 
Os resultados apresentados, na questão 4 vão ao encontro da questão 3 do bloco anterior; ou seja, alguns métodos de estratégias de pesquisas, ainda não são utilizados de forma eficiente pelos respondentes. Já no que se refere ao conhecimento das principais ferramentas da web disponíveis, $87,5 \%$ dos respondentes afirmaram ter conhecimento desta ferramenta, este fato pode ser justificado pelo fato das Diretrizes Curriculares Nacionais para o Curso de Graduação em Ciências Contábeis (Brasil, 2004), estabelecer, em um de seus parágrafos, que uma das competências e habilidades esperadas dos futuros contabilistas, é a capacidade de desenvolver, analisar e implantar sistemas de informações contábeis, o que envolve a capacidade crítica e analítica para avaliar as suas implicações nas empresas, especialmente com a utilização das tecnologias de informação.

Tabela 4 - Resultados obtidos variáveis: Avaliação

\begin{tabular}{c|l|c|c|c|c|c|c|c|c}
\hline Ord. & \multicolumn{1}{|c|}{ Questões } & Sim & $\%$ & Não & $\%$ & Média & D.P & $\begin{array}{c}\text { Média } \\
\text { geral }\end{array}$ & $\begin{array}{c}\text { D. P. } \\
\text { Geral }\end{array}$ \\
\hline 6 & $\begin{array}{l}\text { Mantenho organizadas as } \\
\text { estratégias utilizadas no } \\
\text { passado, relacionadas à procura } \\
\text { avaliação e comunicação da } \\
\text { informação, adotando elas para } \\
\text { orientar para o futuro. }\end{array}$ & 89 & 44,5 & 111 & 55,5 & 0,44 & 0,50 & & \\
\hline 7 & $\begin{array}{l}\text { Acredito que a aprendizagem de } \\
\text { uma nova língua contribui para } \\
\text { uma melhor qualidade e e } \\
\text { efetividade na recuperação da } \\
\text { informação. }\end{array}$ & 177 & 88,5 & 23 & 11,5 & 0,88 & 0,39 & 0,66 & 0,09 \\
\hline
\end{tabular}

Fonte: Dados da pesquisa, 2018.

Sobre a avaliação dos conteúdos encontrados em decorrência da busca de informações, menos da metade dos respondentes, o que equivale a $44,5 \%$, reconheceram que não mantinham um histórico dos procedimentos executados com o intuito de agilizar o processo em futuras recuperações de informações. Tal resultado contraria o que é atribuído ao profissional contábil, que é organizar as informações em suas várias etapas. De fato, Dias Filho e Nakagawa (2001) definem que o sistema de informação contábil é constituído pela geração da mensagem, transmissão, sendo um meio, para o receptor ter subsídios para as tomadas de decisões.

Nesse mesmo bloco de questões, $88,5 \%$ dos respondentes acreditavam 
ser importante ter o domínio de um novo idioma para ampliar o processo de busca e de recuperação das informações. Este resultado vai ao encontro do que é preconizado por Brasil (2004) que estabelece, nas diretrizes para a capacitação profissional contábil, que ele tenha condições de compreender questões científicas, técnicas, sociais, econômicas e financeiras em âmbito nacional e internacional.

Tabela 5 - Resultados obtidos variáveis: Organização

\begin{tabular}{c|l|c|c|c|c|c|c|c|c}
\hline Ord. & \multicolumn{1}{|c|}{ Questões } & Sim & $\%$ & Não & $\%$ & Média & D.P & $\begin{array}{c}\text { Média } \\
\text { geral }\end{array}$ & $\begin{array}{c}\text { D. P. } \\
\text { Geral }\end{array}$ \\
\hline 8 & $\begin{array}{l}\text { Adoto recursos visuais para } \\
\text { confrontar as informações } \\
\text { encontradas. }\end{array}$ & 166 & 83 & 34 & 17 & 0,83 & 0,17 & 0,51 & 0,11 \\
\hline 9 & $\begin{array}{l}\text { Possuo um sistema organizado } \\
\text { de bibliografia pessoal. }\end{array}$ & 38 & 19 & 162 & 81 & 0,19 & 0,39 & & \\
\hline
\end{tabular}

Fonte: Dados da pesquisa, 2018.

Dentre os respondentes, $83 \%$ assumiram possuir recursos visuais para comparar ou contrastar informações. Esta pratica está muito vinculada as práticas que envolvem as análises das demonstrações financeiras, onde a utilização de gráficos, tabelas entre outros, é bastante utilizada, para orientar e buscar simplificar os resultados apresentados aos receptores das informações.

No que se refere à manutenção de uma bibliografia pessoal, grande parte (81\%) afirmaram não possuir este sistema de maneira organizada, o que pode ser justificado pela praticidade das rotinas contábeis; ou seja, no contexto brasileiro, os profissionais da área atuam muito com base na legislação emanada pelos principais órgãos de controles e, devido às constantes alterações destas normas, pode se tornar nula a prática de se manter este sistema organizado.

Tabela 6 - Resultados obtidos variáveis: Utilização

\begin{tabular}{c|c|c|c|c|c|c|c|c|c}
\hline Ord. & Questões & Sim & $\%$ & Não & $\%$ & Média & D.P & $\begin{array}{c}\text { Média } \\
\text { geral }\end{array}$ & $\begin{array}{c}\text { D. P. } \\
\text { Geral }\end{array}$ \\
\hline 10 & $\begin{array}{l}\text { Considero os retornos } \\
\text { oferecidos pelos indivíduos, o } \\
\text { tratando como um princípio } \\
\text { informacional e conhecimento. }\end{array}$ & 191 & 95,5 & 9 & 4,5 & 0,95 & 0,21 & & 0,97 \\
\hline 11 & $\begin{array}{l}\text { Buscar aplicar efetivamente os } \\
\text { novos conhecimentos que me } \\
\text { são oferecidos no meu dia a } \\
\text { dia. }\end{array}$ & 198 & 99 & 2 & 1 & 0,99 & 0,10 & & \\
\hline
\end{tabular}




\begin{tabular}{|c|c|c|c|c|c|c|c|}
\hline 12 & \begin{tabular}{|l} 
Utilizo o conhecimento \\
absorvido para sustentar a \\
minha a tomada de decisão e \\
solucionar problemas.
\end{tabular} & 198 & 99 & 2 & 1 & 0,99 & 0,10 \\
\hline 13 & $\begin{array}{|lrr|}\text { Sei fazer o } & \text { processo de } \\
\text { incorporações } & \text { de } & \text { novas } \\
\text { informações às já existentes, } \\
\text { com o objetivo de criar } \\
\text { soluções } & \text { e } & \text { gerar } \\
\text { conhecimentos. } & & \\
\end{array}$ & 183 & 91,5 & 17 & 8,5 & 0,91 & 0,28 \\
\hline
\end{tabular}

Fonte: Dados da pesquisa, 2018.

Os resultados obtidos com as questões que tratam da utilização da informação evidenciaram que os entrevistados levam em consideração a aplicabilidade da informação, considerando o feedback, o uso das informações para as tomadas de decisões na busca por soluções e na geração de conhecimentos. Este bloco obteve todas as questões com percentual de concordância, acima de 91\%, o que demonstra uma sinergia dos entrevistados com a teoria da comunicação contábil, pois na perspectiva de Guerreiro (1989), a contabilidade é constituída pelo método que envolve a identificação, mensuração e comunicação das informações econômicas das organizações, possibilitando aos seus usuários a tomada das decisões consideradas mais convenientes. Para realizar eficientemente este processo, o profissional contábil deverá estar atualizado, sabendo aplicar as novas tecnologias em suas práticas, conforme já discutido nos resultados da questão 5 .

Tabela 7 - Resultados obtidos variáveis: Comunicação

\begin{tabular}{|c|c|c|c|c|c|c|c|c|c|}
\hline $\begin{array}{c}\text { Ord } \\
.\end{array}$ & Questões & Sim & $\%$ & Não & $\%$ & $\begin{array}{l}\text { Mé- } \\
\text { dia }\end{array}$ & D P & \begin{tabular}{|c} 
Média \\
geral
\end{tabular} & $\begin{array}{l}\text { D. P. } \\
\text { Geral }\end{array}$ \\
\hline 14 & $\begin{array}{l}\text { Aplico os recursos como } \\
\text { equipamentos e ferramentas } \\
\text { multimídia de maneira correta, } \\
\text { conforme o tipo de informação. }\end{array}$ & 172 & 86 & 28 & 14 & 0,86 & 0,35 & \multirow[t]{2}{*}{0,67} & \multirow[t]{2}{*}{0,08} \\
\hline 15 & \begin{tabular}{|l|} 
Explicito informações, vivências, \\
experiências (presencialmente, \\
em redes sociais. blogs, fóruns).
\end{tabular} & 97 & 48,5 & 103 & 51,5 & 0,49 & 0,50 & & \\
\hline
\end{tabular}

Fonte: Dados da pesquisa, 2018.

No que tange à comunicação, 172 respondentes, afirmaram utilizar os equipamentos e ferramentas de maneira correta, o que vai ao encontro dos resultados apresentados na questão 8, que se referem à utilização dos recursos visuais disponíveis. Esses resultados estão também associados à influência das 
tecnologias disponíveis na profissão contábil, conforme aponta LUNELLI (2016), ao mencionar que a conectividade fornecida pela internet elevou o desempenho profissional a um outro patamar, pois as novas tecnologias otimizaram e reduziram o tempo de realização de processos e diminuíram alguns gastos envolvidos.

Já a questão 15 evidenciou que menos da metade dos respondentes, realizam o chamado marketing Digital, por meio das mídias sociais. Tais práticas, principalmente para os profissionais contábeis que irão atuar de maneira autônoma são importantes pois, conforme é destacado por DE OLIVEIRA e LUCENA (2020), elas têm como foco a fidelização dos clientes, possibilitando ao profissional fortalecer sua imagem, ao divulgar os seus trabalhos e experiências profissionais.

Tabela 8 - Resultados obtidos variáveis: Sintetizar

\begin{tabular}{|c|c|c|c|c|c|c|c|c|c|}
\hline Ord. & Questões & Sim & $\%$ & Não & $\%$ & Média & D.P & \begin{tabular}{|c} 
Média \\
geral
\end{tabular} & $\begin{array}{l}\text { D. P. } \\
\text { Geral }\end{array}$ \\
\hline 16 & $\begin{array}{l}\text { Após concentrar e organizar } \\
\text { um número adequado de } \\
\text { informações, realizo a a a de resumos ou } \\
\text { elaboração de das principais } \\
\text { fichamento das } \\
\text { ideias presentes nos achados. }\end{array}$ & 119 & 59,5 & 81 & 40,5 & 0,60 & 0,49 & \multirow[t]{2}{*}{0,73} & \multirow[t]{2}{*}{0,07} \\
\hline 17 & $\begin{array}{l}\text { Após resumir as ideias } \\
\text { principais da informação } \\
\text { reunida, extraio o que tem de } \\
\text { mais relevante. }\end{array}$ & 172 & 86 & 28 & 14 & 0,86 & 0,35 & & \\
\hline
\end{tabular}

Fonte: Dados da pesquisa, 2018.

Em relação à prática de sintetizar as questões, 59,5\% dos entrevistados revelaram organizam suas informações na forma de resumos ou fichamentos. No entanto, grande parte dos entrevistados (86\%) reconheceram extrair as informações mais relevantes para serem apresentadas em seus relatórios contábeis. Estes resultados estão alinhados com uma das características importantes da contabilidade que é a neutralidade. De fato, o Comitê de Pronunciamento Contábeis (CPC), em seu pronunciamento que trata da estrutura conceitual, define como informações relevantes, "aquelas capazes de fazer a diferença nas tomadas das decisões pelos seus usuários", (CONTÁBEIS, 2011). 
Tabela 9 - Resultados obtidos variáveis: Criação

\begin{tabular}{c|c|c|c|c|c|c|c|c|c}
\hline Ord. & Questões & Sim & $\%$ & Não & $\%$ & Média & $\begin{array}{c}\text { Desvio } \\
\text { Padrão }\end{array}$ & $\begin{array}{c}\text { Média } \\
\text { geral }\end{array}$ & $\begin{array}{c}\text { D. P. } \\
\text { Geral }\end{array}$ \\
\hline \multirow{2}{*}{18} & $\begin{array}{l}\text { Busco elaborar produtos } \\
\text { informacionais (vídeos, } \\
\text { áudios, imagens, textos, etc.). }\end{array}$ & 68 & 34 & 132 & 66 & 0,34 & 0,47 & 0,61 & 0,07 \\
\cline { 1 - 5 } 19 & $\begin{array}{l}\text { Sempre faço a análise crítica } \\
\text { da informação e procuro a } \\
\text { transformar em conhecimento. }\end{array}$ & 176 & 88 & 24 & 12 & 0,88 & 0,33 & & \\
\hline
\end{tabular}

Fonte: Dados da pesquisa, 2018.

Com base no resultado e possível identificar que grande parte dos entrevistados afirmaram analisar criticamente a informação, as transformando em conhecimento. Contudo, somente $34 \%$ utilizavam as informações obtidas para transformá-las em algum tipo de produto informacional.

Acredita-se que a questão que se refere a prática de criar novos instrumentos informacionais pode ter sido confundida pelos respondentes como a prática de contabilidade criativa, o que pode ter um entendimento pejorativo é até mesmo sendo confundido como um tipo de fraude. O estudo de NIYAMA et al. (2015), menciona que esse termo pode ser adotado também para determinar o gerenciamento de resultados, que pode envolver a manipulação de resultados dentro do que é permitido pela legislação ou adulterações das informações, aplicadas com o intuito de beneficiar um determinado grupo de pessoas.

Tabela 10 - Resultados obtidos variáveis: Valores Orientados

\begin{tabular}{|c|c|c|c|c|c|c|c|c|c|}
\hline Ord. & Questões & Sim & $\%$ & Não & $\%$ & Média & D.P & $\begin{array}{c}\text { Média } \\
\text { geral }\end{array}$ & $\begin{array}{l}\text { D. P. } \\
\text { Geral }\end{array}$ \\
\hline 20 & $\begin{array}{l}\text { Compreendo o significado e } \\
\text { as implicações relativos a } \\
\text { direitos autorais, domínio } \\
\text { público e copyright. }\end{array}$ & 138 & 69 & 62 & 31 & 0,69 & 0,46 & \multirow{2}{*}{0,77} & \multirow{2}{*}{0,05} \\
\hline 21 & $\begin{array}{l}\text { Julgo questões de } \\
\text { privacidade e segurança } \\
\text { antes de obter e disponibilizar } \\
\text { informações. }\end{array}$ & 171 & 85,5 & 29 & 14,5 & 0,85 & 0,35 & & \\
\hline
\end{tabular}

Fonte: Dados da pesquisa, 2018.

As últimas questões analisadas correspondem aos valores orientados e, neste caso, os resultados demonstram que $69 \%$ dos entrevistados compreendiam o significado e as implicações relativas aos direitos autorais, e $85,5 \%$ afirmavam julgar questões de privacidade e segurança antes de obter e 
disponibilizar informações. Este fator vai ao encontro da Lei Geral de Proteção aos Dados (LGPD), criada com o objetivo de garantir a privacidade das informações dos indivíduos, principalmente no ambiente virtual.

\section{CONSIDERAÇÕES FINAIS}

Avaliar as perspectivas dos usuários da informação e suas habilidades no que tange às competências informacionais se torna necessário para entender como as novas formas de organizar as informações estão chegando a seus usuários e se estão causando algum tipo de impacto positivo na execução das suas atividades profissionais e cotidianas. Nesse sentido, este estudo buscou responder à seguinte indagação: Qual o entendimento dos discentes do curso de Ciências Contábeis sobre algumas práticas vinculadas as competências informacionais?

Com nos resultados, e respondendo ao objetivo geral deste estudo, é possível verificar que os participantes do presente estudo têm um entendimento sobre algumas práticas que envolvem as competências informacionais, mas ainda não estabelecem conexões entre a Ciência da Informação e o curso de Ciências Contábeis, deixando a impressão de que os usuários somente utilizam o que é necessário em determinado momento para satisfazer uma necessidade específica.

Essa distância entre a Ciência da Informação e as Ciências Contábeis se torna mais evidente quando observam-se os termos técnicos. Isso ocorre pelo fato de os profissionais da Área Contábil não terem uma disciplina que direciona e trata da organização da informação em seu curso de graduação.

Diante do exposto, sugerem-se, como pesquisas futuras, verificar quais disciplinas do curso de Ciências Contábeis estão atreladas à Ciência da Informação e quais podem ser acrescidas para o desenvolvimento de algumas competências consideradas de grande relevância para os futuros profissionais contábeis. 


\section{REFERÊNCIAS}

ALVES, C. M. de L. Competência informacional no ambiente de trabalho: habilidades informacionais dos Analistas Legislativos da Assembleia Legislativa do Estado de Minas Gerais. 2011. 111 f. Dissertação (Mestrado em Ciência da Informação) - Universidade Federal de Minas Gerais, Belo Horizonte, 2011.

ASSOCIATION OF COLLEGE RESEARCH LIBRARIES [ACRL]. Information literacy competency standards for higher education. Chicago, IL: American Library Association, 2000. Disponível em:

http://www.ala.org/ala/mgrps/divs/acr//standards/standards.pdf. Acesso em: 07 ago. 2018.

BARROS, V. de M. O novo velho enfoque da informação contábil. Revista Contabilidade \& Finanças, [S.I.], v. 16, n. 38, p. 102-112, 2005.

BELLUZZO, R. C. B. O uso de mapas conceituais e mentais como tecnologia de apoio à gestão da informação e da comunicação: uma área interdisciplinar da competência em informação. Revista Brasileira de Biblioteconomia e Documentação: Nova Série, São Paulo, v. 2, n. 2, p. 78-89, dez, 2006.

BEM, R. M.; COELHO, C. C. de S. R. A relação entre competência informacional e aprendizagem organizacional: um olhar a partir do framework dos 4 I(s). InCID: Revista de Ciência da Informação e Documentação, Ribeirão Preto, v. 5, n. 2, p. 112-127, 2015.

BRANCO, M. C. Uma abordagem institucionalista da contabilidade. Revista Contabilidade \& Finanças - USP, [S.I.], v. 17, n. 42, ISSN 1519-7077, 2006. Disponível em: http://www.redalyc.org/pdf/2571/257119531010.pdf. Acesso em: 07 ago. 2018.

BRASIL. Conselho Nacional de Educação-Câmara de Educação Superior. Resolução CNE/CES no. 10 de 16 de dezembro de 2004. Institui as Diretrizes Nacionais Curriculares para o Curso de Graduação em Ciências Contábeis, bacharelado, e dá outras providências. Legislação Republicana Brasileira, 2004.

BRUCE, C. S. Las siete caras de la alfabetización en información en la enseñanza superior. Annales de Documentación, Espinardo, España, n. 6, p. 289-294, 2003.

CAMPELLO, B. O movimento da competência informacional: uma perspectiva para o letramento informacional. Ciência da Informação, Brasília, v. 32, n. 3 , p. 28-37, 2003. Disponível em: http://www.scielo.br/pdf/ci/v32n3/19021.pdf. Acesso em: 07 ago. 2018.

CAMPELLO, B. A escolarização da competência em informação. Revista Brasileira de Biblioteconomia e Documentação, São Paulo, v. 2, n. 2, p. 6377, dez, 2006. 
CONTÁBEIS, Comitê De Pronunciamentos; DA ESSÊNCIA, Primazia. CPC 00 R1: Estrutura Conceitual para Elaboração e Divulgação de Relatório Contábil-Financeiro. 2011.

DE OLIVEIRA, R. B.; LUCENA, W. M. O uso da Internet e das Mídias Digitais como ferramentas de Estratégia de Marketing. Destarte, [S.I.], v. 2, n. 1, p. 94105, 2020.

DIAS FILHO, J. M.; NAKAGAWA, M. Análise do processo da comunicação contábil: uma contribuição para a solução de problemas semânticos, utilizando conceitos da teoria da comunicação. Revista Contabilidade \& Finanças, [S.I.], v. 12, n. 26, p. 42-57, 2001.

DUDZIAK, E. A. Information literacy: princípios, filosofia e prática. Ciência da Informação, Brasília, v. 32, n. 1, 2006.

EVANGELISTA, A. A. O currículo do curso de Ciências Contábeis e o mercado de trabalho para o profissional contador. 2005. $149 \mathrm{f}$. Dissertação (Mestrado em Controladoria e Contabilidade Estratégica) - Faculdade Escola de Comércio Álvares Penteado, São Paulo, 2005. Disponível em: http://tede.fecap.br:8080/jspui/handle/tede/638\#preview-link0. Acesso em: 07 ago. 2018.

FARIA, S.; OLIVEIRA, V. F. de; FORNER, L.; D'ASTUTO, F. Competências do profissional da informação: uma reflexão a partir da Classificação Brasileira de Ocupações. Ci. Inf., Brasília, v. 34, n. 2, p. 26-33, 2005.

FARIAS, C. M.; VITORINO, E. V. Competência informacional e dimensões da competência do bibliotecário no contexto escolar. Perspectivas em Ciência da Informação, Belo Horizonte, v. 14, n. 2, p. 2-16, jun. 2009.

FINLEY, W.; WAYMIRE, T. Information literacy in the accounting classroom: A collaborative effort. Journal of Business \& Finance Librarianship, [S.I.], v. 17, n. 1, p. 34-50, 2012.

FREITAS, H.; OLIVEIRA, M.; SACCOL, A. Z.; MOSCAROLA, J. O método de pesquisa survey. Revista de Administração, São Paulo, v. 35, n. 3, p. 105112, 2000.

GASPARETTO, V. O papel da contabilidade no provimento de informações para a avaliação do desempenho empresarial. Revista Contemporânea de Contabilidade, Florianópolis, v. 1, n. 2, 2004, p. 109-122, 2004. Disponível em: https://dialnet.unirioja.es/servlet/articulo?codigo=2898142. Acesso em: 07 ago. 2018.

GUERREIRO, R. Modelo conceitual de sistema de informação de gestão econômica: uma contribuição à teoria da comunicação da contabilidade. 1989. 386 f. Tese (Doutorado em Contabilidade) - Universidade de São Paulo, São Paulo, 1989. 
JOHNSTON, B.; WEBBER, S. Information Literacy in Higher Education: A review and case study. Studies in Higher Education, [S.I.], v. 28, n. 3, p. 335352, 2003.

KELLY, A. S.; WILLIAMS, T. D.; MATTHIES, B.; ORRIS, B. Course-integrated information literacy instruction in introduction to accounting. Journal of Business \& Finance Librarianship, [S.I.] v. 16, n. 4, p. 326-347, 2011.

LOUSADA, A. C. Z.; MARTINS, G. de A. Egressos como fonte de informação à gestão dos cursos de Ciências Contábeis. Rev. contab. finanç., São Paulo, v. 16, n. 37, p. 73-84, 2005. Disponível em:

http://www.scielo.br/pdf/rcf/v16n37/v16n37a06.pdf. Acesso em: 07 ago. 2018.

LUNELLI, R. L. A contabilidade e o avanço da tecnologia. Portal de Contabilidade, 2016.

LUPTON, M. Evidence, argument and social responsibility: First-year students' experiences of information literacy when researching an essay. Higher

Education Research and Development, [S.I.], v. 27, n. 4, p. 399-414, 2008.

LUPTON, M.; GLANVILLE, C.; McDONALD, P.; SELZER, D. Information

literacy toolkit. Australia: Griffith Institute for Higher Education, Griffith University, 2004. Disponível em:

https://www.researchgate.net/publication/344198301_Information_Literacy_Tool kit. Acesso em: 24 nov. 2020.

MAÇANEIRO, M. B.; KUHL, M. R. Estado da Arte e o Rumo do Conhecimento Científico em Secretariado Executivo: Mapeamento e Análise de Áreas de Pesquisa. Revista de Gestão e Secretariado, São Paulo, v. 4, n. 3, p. 157188, 2013. Disponível em:

https://www.revistagesec.org.br/secretariado/article/view/274/pdf_49. Acesso em: 07 ago. 2018

MELO, A. V. C. de; ARAÚJO, E. A. de. Competência informacional e gestão do conhecimento: uma relação necessária no contexto da sociedade da informação. Perspectivas em Ciências da Informação, Belo Horizonte, v. 12, n. 2, p. 185-201, maio/ago, 2007.

MIRANDA, S. V. Identificando competências informacionais. Ciência da Informação, Brasília, v. 33, n. 2, p. 112-122, 2004. Disponível em: http://www.scielo.br/pdf/ci/v33n2/a12v33n2.pdf. Acesso em: 07 ago. 2018.

MIRANDA, S. V. Identificação de necessidades de informação e sua relação com competências informacionais: o caso da supervisão indireta de instituições financeiras no Brasil. 2007. 293 f. Tese (Doutorado em Ciência da Informação) - Universidade de Brasília, Brasília, 2007. Disponível em: http://repositorio.unb.br/handle/10482/2903. Acesso em: 07 ago. 2018. 
NIYAMA, J. K.; RODRIGUES, A. M. G.; RODRIGUES, Jomar Miranda.

Algumas reflexões sobre contabilidade criativa e as normas internacionais de contabilidade. Revista Universo Contábil, [S.I.], v. 11, n. 1, p. 69-87, 2015.

NOGUEIRA, V.; FARI, M. A. Perfil do profissional contábil: relações entre Formação e Atuação no mercado de trabalho. Perspectivas

Contemporâneas, [S.I.], v. 2, n. 1, 2007. Disponível em: http://revista.grupointegrado.br/revista/index.php/perspectivascontemporaneas/ article/view/389/183. Acesso em: 07 ago. 2018.

O'FARRILL, R. T. Information Literacy and Knowledge Management: Preparations for an Arranged Marriage. Libri, [s.I.], v. 58, n. 3, p. 155-171, 2008.

PRODANOV, C. C.; FREITAS, E. C. de. Metodologia do trabalho científico: Métodos e Técnicas da Pesquisa e do Trabalho Acadêmico. Novo Hamburgo: Feevale, 2009.

SANTOS, E. M. dos; DUARTE, E. A.; PRATA, N. V. Cidadania e trabalho na sociedade da informação: uma abordagem baseada na competência informacional. Perspectivas em Ciência da Informação, Belo Horizonte, v. 13, n. 3, p. 208-222, 2008.

SAUNDERS, L. Faculty perspectives on information literacy as a student learning outcome. The Journal of Academic Librarianship, [s.I.], v. 38, n. 4, p. 204-232, 2012. Disponível em:

http://dx.doi.org/10.1080/13614533.2014.906351. Acesso em: 07 ago. 2018.

VITORINO, E. V.; PIANTOLA, D. Competência informacional - bases históricas e conceituais: construindo significados. Ciência da Informação, Brasília, DF, v. 38, n. 3, p. 130-141, 2009.

XAVIER, G. M. S.; BRITO, L. M. P.; GURGEL, F. F.; CARVALHO, V. M. Competência informacional: estudo com alunos de curso de Administração, Pretexto, Belo Horizonte, v. 14, n. 4, 2013. Disponível em: http://www.fumec.br/revistas/pretexto/article/view/1881. Acesso em: 07 ago. 2018.

\title{
INFORMATIONAL COMPETENCE IN THE PERSPECTIVE OF ACCOUNTING SCIENCES STUDENTS
}

\begin{abstract}
Introduction: Assessing the perspectives of users of information and their skills with regard to informational competencies is necessary to understand how new ways and ways of organizing information are reaching their users and whether they are causing any positive impact on execution professional and daily activities. Accounting Science is a course in which information management and organization is a necessary input for the efficient performance of professional activities. Thus, seeking to understand the
\end{abstract}


expectations and understanding of students in this area can be an important instrument to understand the impacts of these new skills. Objective: the present study sought to answer the following question: What is the understanding of the students of the Accounting Sciences course about some practices linked to informational competences? Methodology: The research is classified as descriptive, of mixed survey (quali and quanti). For that, descriptive statistics was used. The sample was non-probabilistic, composed of 200 students from the accounting science course from public and private institutions. Results: The results showed that most interviewees had a high percentage of informational skills. Conclusions: Although a high level of knowledge has been presented in the practices involving these competencies, when it comes to practices and terms more usual in Information Science, these percentages decrease considerably, signaling the need for greater integration of these two sciences to increase performance of these future professionals.

Descriptors: Informational Competence. Information Literature. Accounting Sciences. Knowledge management.

\title{
COMPETENCIA INFORMATIVA EN LA PERSPECTIVA DE ESTUDIANTES DE CIENCIAS CONTABLES
}

\begin{abstract}
RESUMEN
Introducción: evaluar las perspectivas de los usuarios de la información y sus habilidades con respecto a las competencias informativas es necesario para comprender cómo las nuevas formas y formas de organizar la información llegan a sus usuarios y si están causando algún impacto positivo en la ejecución de actividades profesionales diarias. Ciencias Contables es un curso en el que la gestión y organización de la información es un insumo necesario para el desempeño eficiente de las actividades profesionales. Por lo tanto, tratar de comprender las expectativas y la comprensión de los estudiantes en esta área puede ser un instrumento importante para comprender los impactos de estas nuevas habilidades. Objetivo: el presente estudio buscó dar respuesta a la siguiente pregunta: ¿Cuál es la comprensión de los alumnos del curso de Ciencias Contables sobre algunas prácticas vinculadas a las competencias informacionales? Metodología: La investigación se clasifica como descriptiva, de encuesta mixta (quali y quanti). Para eso se utilizó estadística descriptiva. La muestra fue no probabilística, compuesta por 200 estudiantes del curso de Ciencias Contables de instituciones públicas y privadas. Resultados: Los resultados mostraron que la mayoría de los entrevistados tenían un alto porcentaje de habilidades informativas. Conclusiones: Si bien se ha presentado un alto nivel de conocimiento en las prácticas que involucran estas competencias, cuando se trata de prácticas y términos más usuales en Ciencias de la Información, estos porcentajes disminuyen considerablemente, señalando la necesidad de una mayor integración de estas dos ciencias para incrementar el desempeño. de estos futuros profesionales.
\end{abstract}

Descriptores: Competencia informativa. Literatura informativa. Ciencias Contables. Conocimiento administrativo.

Recebido em: 22.10 .2019

Aceito em: 21.09.2020 